\title{
Characteristics, sexual behaviour and risk factors of female, male and transgender sex workers in South Africa
}

\author{
M Richter, M Chersich, $M$ Temmerman, $S$ Luchters \\ International Centre for Reproductive Health, Department of Obstetrics and Gynaecology, Ghent University, Belgium \\ M Richter, BA (Hons), MA LLM \\ $\mathrm{M}$ Chersich, MD, MSc, PhD \\ $\mathrm{M}$ Temmerman, $\mathrm{MD}, \mathrm{PhD}$ \\ S Luchters, MD, MSc, PhD
}

African Centre for Migration \& Society, University of the Witwatersrand, Johannesburg, South Africa M Richter, BA (Hons), MA LLM

Centre for Health Policy, School of Public Health, Faculty of Health Sciences, University of the Witwatersrand, South Africa M Chersich, MD, MSc, PhD

School of Public Health, Faculty of Health Sciences, University of the Witwatersrand; Centre for International Health, Burnet Institute, Melbourne, Australia; School of Public Health and Preventive Medicine, Monash University, Victoria, Australia

S Luchters, MD, MSc, PhD

Corresponding author: M Richter (marlise.richter@gmail.com)

\begin{abstract}
Background. In South Africa, information on sex workers' characteristics, sexual behaviour and health needs is limited. Current social, legal and institutional factors impede a safe working environment for sex workers and their clients.

Objectives. To describe characteristics and sexual behaviour of female, male and transgender sex workers, and assess their risk factors for unprotected sex.

Methods. Repeat cross-sectional surveys among sex workers were conducted in Hillbrow, Sandton, Rustenburg and Cape Town in 2010. Sex workers were interviewed once; any re-interviews were excluded from analysis. Unprotected sex was defined as any unprotected penetrative vaginal or anal sex with last two clients.

Results. Trained sex worker-research assistants interviewed 1799 sex workers. Sex work was a full-time profession for most participants. About 8\% (126/1 594) of women, 33\% (22/75) of men, and 25\% (12/50) of transgender people had unprotected sex. A quarter of anal sex was unprotected. Unprotected sex was 2.1 times (adjusted odds ratio (AOR), 95\% CI 1.2 - 3.7; $p=0.011$ ) more likely in participants reporting daily or weekly binge drinking than non-binge drinkers. Male sex workers were 2.9 times (AOR, 95\% CI 1.6 - 5.3; $p<0.001$ ) more likely, and transgender people 2.4 times (AOR, 95\% CI 1.1 - 4.9; $p=0.021$ ) more likely, than females to have unprotected sex. Sex workers in Hillbrow, where the only sex work-specific clinic was operational, were less likely to have unprotected sex than those in other sites.

Conclusion. Tailored sex work interventions should explicitly include male and transgender sex workers, sex work-specific clinics, focus on the risks of unprotected anal sex, and include interventions to reduce harm caused by alcohol abuse.

S Afr Med J 2013;103(4):246-251. DOI:10.7196/SAMJ.6170
\end{abstract}

There is no estimate of sex worker numbers in South Africa (SA), ${ }^{[1]}$ and little is known about the characteristics and health needs of sex workers in the country. Mathematical modelling has estimated that approximately $20 \%$ of new HIV infections in SA are attributable to sex work (sex workers, their clients, and the partners of their clients contribute $5.5 \%, 11.5 \%$ and $2.8 \%$ to new infections, respectively). ${ }^{[2]}$ Even though these figures should be treated with caution because they were based on limited data and a number of assumptions, ${ }^{[2]}$ they point to the significance of sex workers as a key population. Recently, attention and funding has shifted to HIV prevention and treatment within this population, and their occupational health and safety. While some studies have focused on female sex workers (FSWs) in urban centres along major transport routes and in mining areas in SA, these studies are mostly a decade old. ${ }^{[3,4]}$ Moreover, besides research among male sex workers in Kenya and other smaller studies on transgender and male sex workers elsewhere, limited information is available on these populations in Africa. ${ }^{[5]}$

\section{Sex work and risk behaviour}

In 1998, HIV prevalence among different FSW groups in SA ranged between $46 \%$ and $69 \% \cdot{ }^{[3,4,6]}$ In a $2004-2005$ Durban study, 775 women at high risk for HIV infection $-78.8 \%$ of whom selfidentified as sex workers - were screened, and $59.6 \%$ were found to be HIV-positive. ${ }^{[7]}$ More recent estimates are not available. A recent meta-analysis emphasised the considerable risk that HIV poses to FSWs. They have an almost 13 times higher risk of acquiring HIV infection than other women of reproductive age in low- and middleincome countries. ${ }^{8}$ Some clients, forcefully, insist on sex without 
protection, refuse to use condoms, or offer higher fees for sex without condoms. ${ }^{[9]}$ Given the nature of their work, sex workers are often involved in several concurrent sexual partnerships and exposed to a number of risk factors for STIs. Anal sex - a risk factor for HIV often attracts a higher fee than other sex acts. ${ }^{[5]}$ Excessive alcohol use, often associated with sex work, is a risk factor for unprotected sex. ${ }^{[10]}$

Promotion of consistent condom use is the core prevention strategy for sexually transmitted infections (STIs) among sex workers and their partners. Female condoms are one of the few female-controlled HIV prevention technologies available, with some FSWs even using them without clients' knowledge. ${ }^{11}$ Sex workers have advocated for greater availability of female condoms in sex work settings, with little success. The National Department of Health distributed around 5 million female condoms in 2010 - 2011 (target: 6 million) - which is $1 \%$ of the half-a-billion male condoms distributed (target: 1 billion) during the same period. ${ }^{[12]}$

Much of what we know about sex work and STI risk in SA relies on international literature and outdated data. Research gaps compound misunderstandings of sex workers and their marginalisation within health and policy structures. Updated information on sex worker characteristics, sexual behaviour and risk factors for unprotected sex could provide insights for policymakers about the needs of these populations, and guide the formulation of appropriate and sensitive health, social and legal responses.

\section{Methods}

Self-identified female, male and transgender sex workers in Hillbrow, Sandton, Rustenburg and Cape Town were interviewed by trained sex worker-research assistants in May - September 2010. University-based researchers collaborated with two non-governmental organisations the Sex Worker Education and Advocacy Taskforce (SWEAT) and Sisonke Sex Worker Movement. Research sites were chosen according to 2010 Soccer World Cup host cities. ${ }^{[13]}$ Johannesburg, the largest city in SA, had two sites: Hillbrow and Sandton. The inner-city area of Hillbrow was selected as it has an active, long-established sex trade. Sandton, a wealthy suburb and business district in Johannesburg, has a visible sex work industry. The Rustenburg site - in a predominantly rural province - comprises informal settlements within a platinum mining area about 15 kilometres outside the city, where its sex work industry mainly serves the local mining community. The coastal city of Cape Town is a popular international tourist destination, with a visible sex work industry.

Female, male and transgender sex workers (defined as having exchange of sexual services for financial reward') who were 18 years and older were eligible. In sex work venues, sex worker research assistants approached every third individual known to them as a sex worker and invited her/him to participate. Each assistant administered a 43-item semi-structured questionnaire to around 60 sex workers. Questionnaires were adapted from studies with sex workers in Mombasa, Kenya, ${ }^{[14]}$ and research on migration and access to health care in Johannesburg. ${ }^{[15]}$ Questionnaires were translated from English into isiZulu, isiXhosa, Afrikaans and Setswana. More detailed study methods are described in a paper on the 2010 Soccer World Cup and its impact on the sex industry, which documented few changes in FSW demographics over that time. ${ }^{[13]}$

The study was approved by the University of the Witwatersrand Human Research Ethics Committee (Protocol number H100304). Participants provided written informed consent and were offered a cell phone airtime or grocery voucher of 20 South African Rands ( US\$3) for their interview time. Research assistants referred participants to local counselling, health and legal assistance organisations, as required. Participants were given female condoms and information about a toll-free sex worker helpline. As all aspects of sex work are criminalised in SA, no identifying information was collected.

\section{Study measures and statistical analysis}

Socio-demographics, sexual behaviour and condom use are described for the three study groups: females, males and transgender sex workers. Participants were asked if they had other income-generating activities aside from sex work and to specify such activities. Current weekly income from sex work was calculated by multiplying the total number of clients seen in the preceding week by the mean monetary payments from the last two clients. Participants provided information on their last two commercial sex interactions, including type of sex, condom use and whether the sex workers perceived themselves to be drunk during intercourse. We assessed factors associated with unprotected penetrative sex, defined as any unprotected vaginal or anal sex with the last two clients. Questions about female condom use and their acceptability were included. Participants reported their frequency of binge drinking (having five or more alcoholic drinks on one occasion).

Data were double-entered by separate clerks and analysed using Intercooled Stata 11.0 (Stata Corporation, College Station, USA). Descriptive analysis of the population characteristics assessed the distribution of continuous variables and the frequency distribution of categorical variables in contingency tables. Data from repeat interviews with participants who had more than one interview were excluded from analysis. Multivariate logistic regression assessed associations between unprotected sex, and socio-demographics, binge drinking and use of female condoms, controlling for measured confounders. Variables associated with the primary outcome in bivariate analysis $(p<0.1)$ or in similar studies were forced into the initial model and retained if their removal markedly altered model fit.

\section{Results}

\section{Socio-demographics and occupational setting}

Participants were a mean of 30 years old: females 29.7 (SD 6.5), males 30.7 (SD 6.3), and transgender 28.7 years (SD 5.6) (Table 1). Just over half $(53.7 \%$; 878/1 636) of female and male (55.3\%; 48/87) participants, and just over a third $(37.9 \% ; 22 / 58)$ of transgender subjects, were born in SA. A third (555/1 626) of females, $25 \%$ $(21 / 87)$ of males, and $15.8 \%(9 / 57)$ of transgender participants noted that they had a permanent partner $(p=0.003)$. Females were responsible for a median of 4 adult and/or child dependants - twice that of male or transgender participants $(p<0.001)$. Age of sex work debut was similar across the genders: an average of about 24 years. More than $40 \%$ of all participants had been doing sex work for more than 5 years. Among female $(44.8 \% ; 698 / 1558)$ and transgender $(36.8 \%$; $21 / 57)$ participants, indoor venues such as hotels, brothels and massage parlours were the most common locations for soliciting clients. Just over a third of males $(36.6 \% ; 30 / 82)$ and transgender people $(35.1 \%$; $20 / 57)$, and a quarter of females $(24.6 \%$; $383 / 1558)$ worked at a combination of venues that included a mix of street work and/or some indoor venues.

Sex work was a full-time profession for as many as two-thirds of each group. Hairdressing was the most popular other occupation for women $(26.3 \% ; 118 / 449)$ and transgender people $(50 \% ; 8 / 16)$ who were part-time. For males, 25\% (7/27) reported hawking or selling goods to supplement their income. One in 5 women (20.3\%; 91/449) noted that their partner or spouse provided financial support, in contrast with $3.7 \%(1 / 27)$ of men and none of the transgender group. A substantial number reported never having had a job before sex 
Table 1. Characteristics of female, male and transgender sex workers at 4 sites in South Africa $(N=1799)$

\begin{tabular}{|c|c|c|c|}
\hline Variables & Female $(N=1653)$ & Male $(N=87)$ & $\begin{array}{l}\text { Transgender } \\
(N=59)\end{array}$ \\
\hline Age, mean (SD) & $29.7(6.5)$ & $30.7(6.3)$ & $28.7(5.6)$ \\
\hline Education, $n(\%)$ & $N=1587$ & $N=79$ & $N=54$ \\
\hline Incomplete primary school & $299(18.8)$ & $12(15.2)$ & $6(11.1)$ \\
\hline Completed primary school & $812(51.2)$ & $25(31.7)$ & $26(48.2)$ \\
\hline Completed secondary school & $373(23.5)$ & $34(43.0)$ & $18(33.3)$ \\
\hline Received tertiary training & $103(6.5)$ & $8(10.1)$ & $4(7.4)$ \\
\hline Site, $n(\%)$ & $N=1653$ & $N=87$ & $N=59^{\|}$ \\
\hline Hillbrow & $584(35.3)$ & $4(4.6)$ & $0(0)$ \\
\hline Sandton & $271(16.4)$ & $3(3.5)$ & $19(32.2)$ \\
\hline Cape Town & $360(21.8)$ & $64(73.6)$ & $22(37.3)$ \\
\hline Rustenburg & $438(26.5)$ & $16(18.4)$ & $18(30.5)$ \\
\hline Migration status, $n(\%)$ & $N=1636$ & $N=87$ & $N=58^{\|}$ \\
\hline Cross-border migrant & $758(46.3)$ & $22(25.3)$ & $19(32.8)$ \\
\hline Internal migrant (migration between provinces) & $638(39.0)$ & $48(55.2)$ & $22(37.9)$ \\
\hline Non-migrant & $240(14.7)$ & $17(19.5)$ & $17(29.3)$ \\
\hline Relationship status, $n(\%)$ & $N=1626$ & $N=87$ & $N=57 \|$ \\
\hline Single & $1071(65.9)$ & $66(75.9)$ & $48(84.2)$ \\
\hline Regular partner & $555(34.1)$ & $21(24.1)$ & $9(15.8)$ \\
\hline Lives with regular partner, $n / N(\%)$ & $221 / 555(39.8)$ & $9 / 21(42.9)$ & $2 / 9(22.2)$ \\
\hline Number of dependants, median (IQR; range) & $4(2-6 ; 0-37)$ & $2(1-4 ; 0-12)$ & $2(0-3 ; 0-8)^{\|}$ \\
\hline Age at sex work debut (years), mean $( \pm S D)$ & $24.2( \pm 5.3)$ & $23.6( \pm 4.5)$ & $24.3( \pm 5.0)$ \\
\hline Duration in sex work (years), $n(\%)$ & $N=1503$ & $N=69$ & $N=50$ \\
\hline$<1$ & $246(16.4)$ & $11(15.9)$ & $5(10.0)$ \\
\hline $1-5$ & $597(39.7)$ & $27(39.1)$ & $21(42.0)$ \\
\hline$>5$ & $660(43.9)$ & $31(44.9)$ & $24(48.0)$ \\
\hline Main venue solicits clients, $n(\%)$ & $N=1558$ & $N=82$ & $N=57 \|$ \\
\hline Indoors* & $698(44.8)$ & $21(25.6)$ & $21(36.8)$ \\
\hline Outdoors $^{\dagger}$ & $477(30.6)$ & $31(37.8)$ & $16(28.1)$ \\
\hline Combination of venues ${ }^{*}$ & $383(24.6)$ & $30(36.6)$ & $20(35.1)$ \\
\hline Part-time sex worker, $n / N(\%)$ & $449 / 1556(28.9)$ & $27 / 83(32.5)$ & $16 / 55(29.1)$ \\
\hline Other part-time work, ${ }^{\varsigma} n(\%)$ & $N=449$ & $N=27$ & $N=16$ \\
\hline Waiting tables/dancer & $62(13.8)$ & $4(14.8)$ & $2(12.5)$ \\
\hline Tailor/seamstress/fashion & $29(6.5)$ & $1(3.7)$ & $2(12.5)$ \\
\hline Hairdresser/barber & $125(27.8)$ & $5(18.5)$ & $8(50)$ \\
\hline Partner/spouse provides income & $91(20.3)$ & $1(3.7)$ & $0(0)^{\star *}$ \\
\hline Hawking/selling goods & $66(14.7)$ & $7(25.9)$ & $0(0)$ \\
\hline Work before sex work, ${ }^{\S} n(\%)$ & $N=1653$ & $N=87$ & $N=59$ \\
\hline Waiting tables/dancer & $191(11.6)$ & $7(8.1)$ & $5(8.5)$ \\
\hline Tailor/seamstress/fashion & $67(4.1)$ & $3(3.5)$ & $4(6.8)$ \\
\hline Hairdresser/barber & $182(11.0)$ & $15(17.2)$ & $15(25.4)^{\star *}$ \\
\hline Hawking/selling goods/cashier & $180(10.9)$ & $14(16.1)$ & $6(10.2)$ \\
\hline No previous work & $738(44.7)$ & $28(32.2)$ & $19(32.2)^{\|}$ \\
\hline Binge drinking, $n(\%)$ & $N=1566$ & $N=82$ & $N=54^{\|}$ \\
\hline Daily & $284(18.1)$ & $34(41.5)$ & $16(29.6)$ \\
\hline Weekly & $408(26.1)$ & $19(23.2)$ & $20(37.0)$ \\
\hline
\end{tabular}

Continued... 
Table 1 (continued). Characteristics of female, male and transgender sex workers at 4 sites in South Africa ( $N=1799)$

\begin{tabular}{|c|c|c|c|}
\hline Variables & Female $(N=1653)$ & Male $(N=87)$ & $\begin{array}{l}\text { Transgender } \\
(N=59)\end{array}$ \\
\hline Never & $380(24.3)$ & $10(12.2)$ & $4(7.4)$ \\
\hline Full-time weekly income (Rands), median (IQR; range) ${ }^{9}$ & $\begin{array}{l}1500(665-3740 \\
0-64000)\end{array}$ & $\begin{array}{l}2000(1000- \\
5850 ; 0-56250)\end{array}$ & $\begin{array}{l}2750 \|(1275- \\
4200 ; 0-25650)\end{array}$ \\
\hline $\begin{array}{l}\mathrm{SD}=\text { standard deviation; } \mathrm{IQR}=\text { interquartile range. } \\
{ }^{*} \text { Indoors includes working from brothels, bars or massage parlours. } \\
\text { Outdoors includes street-based sex workers. } \\
\text { F Indoor and/or outdoor venues. } \\
\text { \$ Multiple-response question. } \\
\text { OUS } \$ 1=7.5 \text { South African Rands. } \\
\text { Ip<0.05, testing distribution of variables with mutually-exclusive categories. } \\
* * 00.05 \text {, testing distribution of each category of variables with multiple respo }\end{array}$ & nding per variable). & & \\
\hline
\end{tabular}

Table 2. Sexual behaviour and condom use of female, male and transgender sex workers at 4 South African sites $(N=1799)$

\begin{tabular}{|c|c|c|c|}
\hline Variables & Female $(N=1653)$ & Male $(N=87)$ & Transgender $(N=59)$ \\
\hline Number of clients, median in last week, $n$ (IQR) & $12(6-20)$ & $10(5-20)$ & $8(4-15)$ \\
\hline Penetrative sex with last client, $n / N(\%)$ & $1522 / 1653(92.1)$ & $71 / 87(81.6)$ & $48 / 59(81.4)$ \\
\hline Any penetrative sex with last two clients, $n / N(\%)$ & $1614 / 1653(97.6)$ & $77 / 87(88.5)$ & $53 / 59(89.8)$ \\
\hline Type of intercourse with last client, $n(\%)$ & $N=1653$ & $N=87$ & $N=59$ \\
\hline Vaginal & $1456(88.1)$ & $8(9.2)$ & $9(15.3)$ \\
\hline Anal & $87(5.3)$ & $61(70.1)$ & $39(66.1)$ \\
\hline Oral & $207(12.5)$ & $20(23.0)$ & $8(13.6)$ \\
\hline Masturbation & $49(3.0)$ & $12(13.8)$ & $4(6.8)$ \\
\hline Drunk during last paid sex, $n / N(\%)$ & $651 / 1603(40.6)$ & $49 / 82(59.8)$ & $37 / 56(66.1)$ \\
\hline Unprotected penetrative sex with last client, $n / N(\%)^{*}$ & $82 / 1498(5.5)$ & $19 / 69(27.5)$ & $9 / 45(20.0)$ \\
\hline Any unprotected penetrative sex with last two clients, $n / N(\%)^{*}$ & $126 / 1594(7.9)$ & $22 / 75(29.3)$ & $12 / 50(24.0)$ \\
\hline Ever used female condoms, $n / N(\%)$ & $446 / 1006(44.3)$ & $4 / 46(8.7)$ & $8 / 39(20.5)$ \\
\hline
\end{tabular}

work: $33 \%(28 / 87)$ of men and of transgender people (19/59), and $44.7 \%$ (738/1 653) of women. Median weekly income from full-time sex work differed across the genders: R1 500 ( US\$200) for females (IQR 665 - 3740 , range 0 - 64000 ), R2 000 ( US\$266) for males (IQR 1000 - 5850 , range 0 - 56250 ) and R2 750 ( US\$366) for transgender people (IQR 1275 - 4 200, range 0 - 25 650; $p<0.001$ ).

About 20\% (284/1 566) of females, 33\% (16/54) of transgenders and $>40 \%(34 / 82)$ of males reported daily binge drinking. Only $25 \%$ (380/1566) of females, $12.2 \%(10 / 82)$ of males, and $7.4 \%(4 / 54)$ of transgenders said they never did any binge drinking.

\section{Sexual behaviour, condom use and alcohol use}

The median number of clients in the week preceding study enrolment was 12,10 and 8 for females, males and transgender persons respectively (Table 2 ). More women had penetrative sex with last client $(92.1 \% ; 1522 / 1653)$ than males $(81.6 \% ; 71 / 87 ; p<0.001)$ or transgenders (81.4\%; $48 / 59 ; p<0.001)$, while women were less likely to have unprotected sex: $5.5 \%(82 / 1498)$ of women had unprotected sex with last client in contrast with $27.5 \%(19 / 69 ; p=0.01)$ of men, and $20.0 \%(9 / 45 ; p<0.001)$ of transgenders.

Close to $8 \%(126 / 1594)$ of women, $33 \%$ (22/75) of men and $25 \%$ $(12 / 50)$ of transgenders reported any unprotected sexual intercourse with last 2 clients. In multivariate analysis, males were 2.9 times (AOR 95\% CI 1.6 - 5.3; $p<0.001$; data not shown) more likely, and transgender people 2.4 times (AOR, 95\% CI $1.1-4.9 ; p=0.021$ ) more likely, than females to have unprotected anal/vaginal sex with last clients. In univariate analysis, having fewer dependants was associated with unprotected sex, but this association did not persist in multivariate analysis. Cape Town sex workers were 5.5 times (AOR 95\% CI 3.0 - 10.0; $p<0.001$ ), those in Rustenburg 2.9 times (AOR $95 \%$ CI 1.6 - 5.3; $p<0.001$ ) and those in Sandton 2.7 times (AOR $95 \%$ CI $1.4-5.1 ; p=0.04)$ more likely to engage in unprotected sex than those in Hillbrow. Women soliciting clients outdoors were 0.59 times less likely to have unprotected sex than those working indoors (AOR 95\% CI 0.3 - 0.8), who had similar levels to those working at a combination of venues.

Nine out of 10 (1 456/1 653) female sex workers had vaginal, and $5.3 \%(87 / 1653)$ had anal, sex with their last client. Seventy per cent of males (61/87) had anal sex with last client - as did 66.1\% (39/59) of transgenders. Of all sexual encounters with last clients, $73.0 \%$ (149/204) of participants who had anal sex used condoms; $94.0 \%$ used them (1 419/1 508) with vaginal sex, 76.9\% (186/242) with oral sex, and $65.2 \%$ (45/69) during masturbation (data not shown).

More than $40.0 \%$ of females (651/1 603) were drunk during sex with last client, in comparison with 59.7\% (49/82) of males and 66.1\% (37/56) of transgenders. Feeling drunk during sex with any of their last two clients was reported by $13.2 \%$ (113/858) of all participants. In univariate analysis, women who reported being drunk with any of their last two clients, were 2.6 times (95\% CI $1.7-3.8 ; p<0.001$ ) more likely to have unprotected sex than those women who were 
not drunk. Participants who reported daily or weekly binge drinking were 2.1 times (AOR 95\% CI 1.2 - 3.7; $p=0.011$ ) more likely than those who never engaged in binge drinking, to have unprotected sex.

Slightly less than half (446/1 006) of female participants had ever used a female condom. Of these, close to a third (116/413) 'liked' them, and almost half (189/413) 'liked them a lot' (data not shown). Only 7.5\% (31/413) disliked female condoms, with 77/413 (18.6\%) being neutral. Among those female participants who did not use female condoms and provided reasons for non-use, about a fifth (99/560) each noted that they had never been given female condoms, did not know how to use them $(111 / 560)$ or did not like them (129/560). A further approximate tenth (66/560) noted either that they were unfamiliar with female condoms or that clients precluded their use $(47 / 560)$.

\section{Discussion}

Sex work was the major livelihood strategy adopted by the study populations: more than $40 \%$ had been in the industry for more than 5 years; approximately two-thirds worked full-time, while over a third had no prior work experience. When comparing full-time sex workers' income with data from Statistics South Africa (national statistics board) on monthly earnings by occupation, sex workers in this study, though most had never completed secondary schooling, were earning more than clerks, sales and services, crafts and related trades, and up to 6 times more than domestic workers. ${ }^{16}$ This echoes a previous study, which found that Cape Town-based sex workers' earning capacity was 2.6 - 4 times higher in sex work than their previous employment. ${ }^{[17]}$ This is pertinent for some ideology-based health and social interventions aiming to 'rehabilitate' sex workers or focus solely on 'exit programmes'.

The high levels of binge drinking found among all gender groups in our study support findings in a Pretoria study where sex workers had high levels of alcohol consumption and alcohol dependency. ${ }^{[18]}$ Daily or weekly binge drinking was linked with unprotected sex. Other studies confirmed that alcohol interventions with this population are vital for improving the safety of this occupation. ${ }^{[19]}$

Under half (44.3\%) of female participants had ever used a female condom. Of these, $75 \%$ favoured such condoms. Studies in SA have demonstrated acceptability of female condoms ${ }^{[20]}$ and their re-use ${ }^{[21]}$ and cost-effectiveness. ${ }^{[2]}$ As a female-controlled infection prevention strategy, this should be a vital component of sex work interventions.

It is of concern that males were 2.9 times more likely, and transgenders 2.4 times more likely, than female sex workers to engage in unprotected sex. This could reflect the dearth of programmes focusing on males and transgender sex workers or the general lack of information on anal sex, ${ }^{[23]}$ and is an area needing action. Of all participants, $27 \%$ had unprotected sex for anal intercourse with last client - the most risky sex act for acquiring HIV. Public health interventions with female, male and transgender sex workers and their clients should emphasise the risks associated with anal sex and ensure that condoms and lubrication are accessible and freely available within the sex industry.

Sex workers in the Sandton, Rustenburg and Cape Town sites were significantly more likely to engage in unprotected sex than those in Hillbrow. Hillbrow had the only sex work-specific clinic and mobile outreach clinical services for sex workers at the time of the study. A cadre of sex work peer educators disseminate information and condoms within hotels and clubs from where sex workers operate, while male community health workers provide HIV/STI education and referrals to clients in bars and nightclubs. This model should be replicated in other areas of sex work concentration in SA.
The study included self-reported data only and was based on a non-random sampling design. Surveys were, however, conducted by trained peer interviewers, which may have reduced the socialdesirability bias in respondents' answers. Though trained, some interviewers omitted noting data on some key questions. Almost all peer interviewers were female, which may have affected the number of male and transgender subjects who were approached for participation. Selected research sites included 2 urban centres and 1 semi-rural site adjacent to a mine and were purposively selected, based on the presence of sex worker advocacy groups and peer education work. Although we aimed to obtain data on diverse sex work settings, these findings may not apply to other sex work areas in SA.

In conclusion: sex workers in SA remain at high risk of HIV and other STIs. This risk has been acknowledged by SA AIDS policies and sex work-specific programmes proposed since the first National AIDS Plan in 1994, yet little action has been taken. The National Strategic Plan for HIV and AIDS, STIs and TB, 2012-2016 contains a number of sex work-specific health and non-discrimination provisions, and should be implemented as a matter of urgency.

Acknowledgements. We thank the Sex Worker Education and Advocacy Taskforce (SWEAT) and Sisonke Sex Worker Movement for guidance and logistical support, and the research assistants for data collection. Technical and logistical support of the African Centre for Migration \& Society and the Centre for Health Policy, University of the Witwatersrand and their students was key to conceptualising and developing the project, together with assistance of the Sex Work Project, Wits Reproductive Health and HIV Institute in Hillbrow. Authors gratefully acknowledge the contribution to this work of the Victorian Operational Infrastructure Support Program. Special thanks for their contributions are extended to Jo Vearey, Dianne Massawe, Carolin Kueppers, Tom Considine, Fiona Scorgie, Elsa Oliveira, Agnieszka Flak, Marc Lewis, Ingrid Palmary, Richard Steen, Gerrit Maritz, Francois Venter and Ziad El-Khatib. Funding for this study was provided by UNFPA and Atlantic Philanthropies, while support from the Humanities Graduate Centre and the SPARC Fund at the University of the Witwatersrand facilitated drafting of the manuscript.

\section{References}

1. Vandepitte J, Lyerla R, Dallabetta G, Crabbe F, Alary M, Buve A. Estimates of the number of female sex workers in different regions of the world. Sexually Transmitted Infections 2006;82 Suppl 3:18-25. [http://dx.doi.org/10.1136/sti.2006.020081]

2. SACEMA. The Modes of Transmission of HIV in South Africa - An HIV incidence modelling complo South African Centre for Epidemiological Modelling and Analysis (SACEMA) and the University of South African Centre for

the Witwatersrand, 2009

Rees H, Beksinska ME, Dickson-Tetteh K, Ballard RC, Htun YE. Commercial sex workers in Johannesburg: risk behaviour and HIV status. South African Journal of Science 2000;96:283-284.

4. Ramjee G, Karim SS, Sturm AW. Sexually transmitted infections among sex workers in KwaZulu-Natal, South Africa. Sexually Transmitted Diseases 1998;25(7):346-349. [http://dx.doi.org/10.1097/00007435199808000-00004]

5. Scorgie F, Chersich MF, Ntaganira I, Gerbase A, Lule F, Lo YR. Socio-demographic characteristics an behavioral risk factors of female sex workers in sub-saharan Africa: a systematic review. AIDS and Behavior 2012;16(4):920-933. [http://dx.doi.org/10.1007/s10461-011-9985-z]

6. Williams BG, Taljaard D, Campbell CM, et al. Changing patterns of knowledge, reported behaviour and sexually transmitted infections in a South African gold mining community. [Miscellaneous]. AIDS 2003;17(14):2099-2107. [http://dx.doi.org/10.1097/00002030-200309260-00011]

7. van Loggerenberg $\mathrm{F}$ Mlisana $\mathrm{K}$, Williamson $\mathrm{C}$, et al. Establishing a cohort tat high risk of $\mathrm{HIV}$ infection in South Africa: C, Mlisana $\mathrm{K}$, Williamson C, et al. Establishing a cohort at high risk of HIV infectio in South Africa: Challenges and experiences of the CAPRISA 002 Acute Infection Study. PLoS ONE

. Bent S, Beyrer C, Muessig K, et al. Burden of HIV among female sex workers in low-income and middle-income countries: a systematic review and meta-analysis. Lancet Infect Dis 2012 epub 20 March 2012. [http://dx doi.org/10.1016/S1473-3099(12)70066-X]

9. Pauw I, Brener L. 'You Are Just Whores: You Can't Be Raped': Barriers to safer sex practices among women street sex workers in Cape Town. Culture, Health \& Sexuality 2003;5(6):465-481. [http:// dx.doi.org/10.1080/136910501185198

10. Chersich M, Rees H, Scorgie F, Martin G. Enhancing global control of alcohol to reduce unsafe se and HIV in sub-Saharan Africa. Global Health 2009;5:16. [http://dx.doi.org/10.1186/1744-8603-5-16]

11. Busza J, Baker S. Protection and participation: an interactive programme introducing the female condom to migrant sex workers in Cambodia. AIDS Care 2004;16(4):507-518. [http://dx.doi.org/10 .1080/09540120410001683457

12. Department of Health. Annual Report 2010/2011. Pretoria: Department of Health, 2012. 
13. Richter M, Luchters S, Ndlovu D, Temmerman M, Chersich MF. Female sex work and international sport events - no major changes in demand or supply of paid sex during the 2010 Soccer World Cup: a cross-
sectional study. BMC Public Health 2012;12(1):763. [http://dx.doi.org/10.1186/1471-2458-12-763]

14. Luchters S, Chersich MF, Rinyiru A, et al. Impact of five years of peer-mediated interventions on sexual behavior and sexually transmitted infections among female sex workers in Mombasa, Kenya. BMC behavior and sexually transmitted infections among female sex workes

15. Vearey J. Migration, access to ART, and survivalist livelihood strategies in Johannesburg. African Journal of AIDS Research 2008;7(3):361-374. [http://dx.doi.org/10.2989/AJAR.2008.7.3.13.660]

16. Statistics South Africa. Monthly earnings of South Africans, 2010. Pretoria: Statistics South Africa, 2010

17. Gould C, Fick N. Selling sex in Cape Town: Sex Work and Human Trafficking in a South African city. Pretoria: Institute for Security Studies, 2008

18. Wechsberg W, Luseno W, Lam W, Parry C, Morojele N. Substance use, sexual risk, and violence: HIV prevention intervention with sex workers in Pretoria. AIDS and Behavior 2006;10(2):131-137. [http:// dx.doi.org/10.1007/s10461-005-9036-8]

19. Chersich MF, Luchters SM, Malonza IM, Mwarogo P, Kingola N, Temmerman M. Heavy episodic drinking among Kenyan female sex workers is associated with unsafe sex, sexual violence drinking among Kenyan female sex workers is associated with unsafe sex, sexual violence
and sexually transmitted infections. Int J STD AIDS 2007;18(11):764-769. [http://dx.doi. org/10.1258/095646207782212342]
20. Joanis C, Beksinska M, Hart C, Tweedy K, Linda J, Smit J. Three new female condoms: which do South African women prefer? Contraception 2011;83(3):248-254. [http://dx.doi.org/10.1016/j. contraception.2010.08.002

21. Pettifor AE, Beksinska ME, Rees HV, Mqoqi N, Dickson-Tetteh KE. The acceptability of reuse of the female condom among urban South African women. Journal of Urban Health 2001;78(4):647-657. [http://dx.doi.org/10.1093/jurban/78.4.647]

22. Marseille E, Kahn JG, Billinghurst K, Saba J. Cost-effectiveness of the female condom in preventing HIV and STDs in commercial sex workers in rural South Africa. Social Science \& Medicine 2001;52(1):135. [http://dx.doi.org/10.1016/S0277-9536(00)00282-3]

23. Scheibe A, Brown B, Duby Z, Bekker L-G. Key Populations, Key Responses. A Gap Analysis for Key Populations and HIV in South Africa, and Recommendations for the National Strategic Plan for HIV/ AIDS, STIs and TB (2012-2016). Cape Town: Desmond Tutu HIV Foundation, Joint UN Team on HIV and AIDS, 2011.

Accepted 27 November 2012. 